\title{
El Consenso de Washington: algunas implicaciones para América Latina
}

\author{
The Washington Consensus: some \\ Implications for Latin America
}

O consenso de Washington: algumas implicações para América Latina

\author{
Víctor Mauricio Castañeda Rodríguez \\ Ómar Díaz-Bautista*
}

* Doctor en Ciencias Económicas. Profesor asociado de la Facultad de Ciencias Económicas y Administrativas de la Universidad Jorge Tadeo Lozano. Bogotá, Colombia. victorm.castanedar@utadeo.edu.co [1] http://orcid.org/00000001-8343-6739

** Magíster en Ciencias Económicas. Profesor asociado de la Facultad de Ciencias Económicas y Administrativas de la Universidad Jorge Tadeo Lozano. Bogotá, Colombia. omar.diazb@utadeo.edu.co 


\title{
Resumen
}

Tras la crisis de la deuda externa, diversos países de América Latina emprendieron amplias reformas económicas orquestadas por organismos multilaterales como el FMI, las cuales se alineaban con las pautas que hacían parte del Consenso de Washington. Sin embargo, tras más de 25 años de aplicación del citado Consenso, son contradictorios muchos de los resultados alcanzados en materia económica y social en la región, por lo que en este documento, además de revisar algunas falencias en su concepción, se consideran ciertas recomendaciones de ajuste, especialmente en el área tributaria. En general, se establece que la falta de coherencia interna del modelo y lo endeble de ciertas hipótesis en que se fundamentó, como la presunta ineficiencia del Estado, limitaron el cumplimiento de sus objetivos.

Palabras clave: Consenso de Washington, América Latina, reformas económicas, reformas tributarias.

Clasificación JEL: D78, E62, G28

\begin{abstract}
Many countries in Latin America undertook sweeping economic reforms in response to the debt crisis, which were fostered by multilateral agencies such as the IMF and were aligned with the guidelines offered by the Washington Consensus. However, and after more than 25 years of application, many results achieved under the said consensus in economic and social matters are contradictory; therefore, this document reviews some shortcomings of its design and considers certain recommendations of adjustment, particularly in taxation. The paper states that the lack of internal consistency of the model and the weakness of certain assumptions on which it was based, such as the alleged inefficiency of State, limited the fulfillment of its objectives.
\end{abstract}

Keywords: Washington Consensus, Latin America, economic reforms, tax reforms. 


\section{Resumo}

Muitos países da América Latina empreenderam profundas reformas econômicas em resposta à crise da dívida, que foram sustentados por agências multilaterais como o FMI e foram alinhadas com as diretrizes oferecidas pelo Consenso de Washington. No entanto, e depois de mais de 25 anos de aplicação, muitos resultados alcançados no âmbito do referido consenso em questões económicas e sociais são contraditórias; portanto, este documento analisa algumas deficiências de seu projeto e considera certas recomendações de ajuste, especialmente na tributação. $\mathrm{O}$ documento afirma que a falta de coerência interna do modelo e a fraqueza de certos pressupostos em que se baseou, como a alegada ineficiência do Estado, limitou o cumprimento dos seus objectivos.

Palavras-chave: Consenso de Washington, América Latina, reformas econômicas, Reformas fiscais. 


\section{INTRODUCCIÓN}

El Consenso de Washington (CW) fue tomado por una buena parte de los países de América Latina (AL) y de organismos multilaterales (FMI y BM) como un referente de política económica desde mediados de los ochenta, en que se promovía el crecimiento, la estabilidad macroeconómica y una esperada reducción de la pobreza, a la vez que se buscaba conjurar la crisis de la deuda externa. En efecto, se definió una agenda inicial que fue ajustada a medida que las condiciones macroeconómicas y los postulados con base en la teoría neoclásica así lo requerían, para establecer políticas de primera, segunda y tercera generación.

Estos ajustes se implementaron después de 1985, pero su gradualidad y profundización han dependido del contexto político, económico y social de cada país, lo que explica que los resultados en materia económica y social difieran en la región, pese a algunas tendencias comunes. En general, en este documento se argumenta que los objetivos centrales del Consenso de Washington resultaron contradictorios en la práctica y que las metas se cumplieron parcialmente en términos de crecimiento, mas no así en cuanto a equidad, estabilidad macroeconómica y pobreza.

Lo anterior se debió, al menos en parte, a que las políticas del citado Consenso carecían de coherencia interna, como en el caso de los tratos diferenciales que se consideraron para el capital y el trabajo, lo que ha favorecido una distribución factorial concentrada en las rentas del capital (Jiménez, 2015). Además, se privilegió el crecimiento económico al considerarse como una condición 
necesaria para posteriormente lograr mejoras en indicadores sociales como el margen de pobreza, sin tener en cuenta que no existía ningún argumento teórico o práctico que asegurara que los frutos del crecimiento beneficiarían en especial a la población vulnerable.

Por otra parte, se observa la dualidad de las políticas al hacer las reformas en función de los intereses del capital, sin considerar el interés general o, incluso, en detrimento de este. Se propició, por ejemplo, el incremento de los impuestos al consumo (i.e., IVA), medida de carácter regresivo, mientras que se redujeron los impuestos sobre la renta (ISR) (Castañeda, 2012), lo cual constituye una limitación del grado de progresividad y equidad vertical del sistema tributario. Dicha dualidad favoreció el crecimiento de la pobreza e inequidad a lo largo de los noventa en América Latina.

Este documento muestra cómo el cambio del papel del Estado, de un agente interventor a otro que se limitaba a regular en pro del mercado, no solo generó nuevas oportunidades de negocio para el sector privado, sino que además promovió la aparición de nuevos factores de inestabilidad económica e hizo más vulnerables algunos sectores de la población, como el de los trabajadores. En este orden de ideas, autores como López-Calva y Lustig (2010) sostienen que una inflexión en la tendencia de creciente pobreza e inequidad de los noventa se asocia con fenómenos que supusieron un retroceso o limitación del alcance de las políticas del Consenso de Washington.

Este trabajo incluye otras cinco partes, además de esta introducción. Primero se revisan algunas generalidades del Consenso, para enseguida dar cuenta de algunos actores que se beneficiaron de este cambio en el rumbo de la política pública y del rol asignado al Estado. En la tercera sección se profundiza en la dinámica de ciertos indicadores económicos y sociales (e.g., crecimiento económico, inflación, pobreza y desigualdad) durante los noventa, década en que se aplicaron con especial empeño los puntos tratados por el Consenso; y en la cuarta parte se consideran algunas recomendaciones en materia tributaria, teniendo en cuenta que esta fue una de las áreas más reformadas, pese a los efectos nocivos que implicaba concentrar la recaudación en impuestos al consumo como el IVA. Al final se presentan las conclusiones.

\section{GENERALIDADES DEL CONSENSO DE WASHINGTON}

En primer lugar, es conveniente revisar algunos de los preceptos propios del Consenso de Washington, que contempla la aplicación de principios neoliberales en aspectos puntuales. Después de este análisis, se logrará dilucidar qué sectores o intereses resultaron beneficiados tras su adopción en América Latina y, complementariamente, se podrá determinar cuál fue su costo social. El objetivo central de este aparte es mostrar cómo las políticas del Consenso 
adolecen de falta de coherencia interna $y$ en realidad se constituyen en una estrategia que favorece el cumplimiento del servicio de la deuda por parte de un Estado, de manera que los costos de la reforma terminan siendo soportados por los ciudadanos del común.

Según Williamson (2004), el término acuñado en 1989 y que aparecía explícitamente en un documento para la conferencia del Institute for International Economics, obedecía a una petición del director en aquel entonces del Instituto, Fred Bergsten. En particular, Bergsten consideraba pertinente convocar a una conferencia donde se pusieran a prueba y extendieran los argumentos dados por Williamson ante algunos congresistas de Estados Unidos sobre ciertos cambios significativos en la política económica y el respectivo proceso seguido por
América Latina tras la crisis de la deuda externa (Williamson, 2004).

Básicamente, los diez instrumentos de política que se presentaban como adecuados para velar por la sostenibilidad y el crecimiento de los países deudores y específicamente de los países latinoamericanos (Tabla 1), se desarrollaban como medidas apropiadas ante el fracaso de las políticas empleadas por estos últimos desde 1950. El término Consenso de Washington surgió precisamente del favoritismo que las políticas expresadas en el documento What Washington means by policy reform recibían de buena parte de los altos mandos de la tecnocracia con sede en Washington, como las instituciones financieras internacionales, las agencias económicas de Estados Unidos y la Reserva Federal.

Tabla 1. Reformas que constituían la lista inicial de Williamson (1990)

1. Disciplina fiscal

2. Reordenamiento de las prioridades de gasto público

3. Reforma tributaria (sistema con amplias bases y tasas marginales moderadas)

4. Liberalización de las tasas de interés

5. Tasas de cambio competitivas

6. Liberalización comercial

7. Liberalización de la inversión extranjera directa

8. Privatización

9. Desregulación

10. Derechos de propiedad

Fuente: elaboración propia con base en Williamson (1990). 
Sin embargo, dichas políticas en general no implicaron un mayor bienestar en los países latinoamericanos que las adoptaron, lo que para Williamson respondía a una mala interpretación de las medidas consignadas en la lista de 1989 o a su aplicación incompleta, citando como ejemplo la experiencia argentina con una tasa de cambio fija que desencadenó la crisis de 2001. Así, hacia 2003 se consideró que era necesario incorporar algunas medidas a la versión original del Consenso de Washington, como la liberalización del mercado laboral desmontando algunas prestaciones sociales, para favorecer la formalización de la economía; la mejora institucional en aspectos como la capacidad judicial y la disminución de la corrupción; y la reformulación del gasto concentrándolo en aquellas áreas con mayor utilidad social ${ }^{1}$ (Williamson, 2004).

En particular, Williamson (2004) reformuló su lista de políticas presentada en 1989, ampliando sus alcances y haciendo hincapié en la necesidad de optar por la aplicación del modelo como un todo. Sin embargo, es interesante notar que la aplicación de las políticas económicas sustentadas en el Consenso de Washington no favorecieron el crecimiento económico y, en su lugar, parecen haber sido más funcionales para propiciar el pago de la deuda externa y en general permitir la recuperación de los capitales invertidos por las instituciones financieras en países en vía de desarrollo como los latinoamericanos.
Con respecto a la consistencia interna del Consenso, se debe considerar que este tiene una formulación en que confluyen diversos enfoques. Basta señalar que aspectos como la flexibilidad se denotan de manera distinta según el mercado al que se haga referencia. Si se habla del mercado de bienes y capitales, por ejemplo, el discurso se fundamenta en la eliminación de las barreras comerciales y del control a los capitales, pues se presume que ellas restringen la explotación de las ventajas comparativas de los países y la ubicación de los recursos en aquellos lugares en que su productividad marginal es más alta.

Por otro lado, si se considera el mercado laboral, la flexibilidad ya no se relaciona con la posibilidad del ciudadano común de trasladarse a aquellas regiones o países en que encuentra una demanda efectiva para sus cualidades y habilidades, sino que el elemento central resulta ser el precio del trabajo o salario (Giraldo, 2009). Según el modelo, los factores salariales deben responder a la asignación que hace el mercado de acuerdo con la participación del trabajo en la producción, lo cual lleva a la eliminación de prestaciones sociales "extraordinarias" y a la fijación de salarios mínimos.

El Consenso de Washington fundamenta sus recomendaciones bajo el supuesto de que el mercado es el asignador por excelencia de los recursos escasos, pero paradójicamente no incorpora

Por ejemplo, se proponía concentrar los subsidios a la educación en el nivel primario. 
la movilidad de factores en todos los casos. Además, las recomendaciones del Consenso y sus revisiones van más allá de los preceptos de la teoría clásica, que explica el intervencionismo estatal por la existencia de externalidades en el mercado, pues se precisa que las fallas de la intervención estatal podrían ser incluso más graves que las fallas del mercado que se pretenden corregir (Giraldo, 2009).

Es así que la función del Estado, de acuerdo con el Consenso, debe estar restringida a unas pocas actividades como la provisión de la seguridad nacional y la administración de la justicia, en que deben prevalecer herramientas legales que permitan velar por el cumplimiento de los contratos. Por otra parte, políticas de universalización en áreas como la educación y la salud se ven como inadecuadas, dado que no permiten maximizar la utilidad de los recursos limitados que se destinan a tal fin, pues se asume que gran parte de estos es capturada por individuos que no requieren de la asistencia del Estado.

De esta manera, existe una brecha entre los preceptos neoliberales planteados por autores como Hayek, quien claramente manifiesta su preocupación en torno a las externalidades del mercado, y la importancia de la intervención estatal. Según Hayek (2004, p. 40), el Estado debe:

Crear las condiciones en que la competencia actuará con toda la eficacia posible, complementarla allí donde no pueda ser eficaz y suministrar los servicios que [...] aunque puedan ser ventajosos en el más alto grado para una gran sociedad, son [...] de tal naturaleza que el beneficio nunca puede compensar el gasto de un individuo o de un pequeño número de ellos.

Ahora bien, pese a la resistencia que cabía esperar por parte de diversos sectores como los sindicatos y la población en general, ante una reorganización de la intervención estatal como la planteada por las políticas de la Tabla 1, un factor que jugó a su favor fue el contexto espaciotemporal en que se manifestaba el fracaso del keynesianismo. De acuerdo con Rodrik (1996, p. 13) "la nueva ortodoxia se erigió a partir de dos pilares: "[...] la falla de los países que siguieron el modelo de sustitución de importaciones y el [...] éxito del conjunto de políticas consideradas por los denominados tigres del sureste asiático"2.

En efecto, desde el Consenso de Washington se señaló a la indisciplina fiscal de los Estados, dada su preocupación por auspiciar políticas proteccionistas de fomento a la industria nacional, como causante de la crisis económica de la deuda externa. No obstante, es igualmente razonable presentar el incremento del déficit y la inestabilidad fiscal como consecuencias de la recesión, pues los ingresos tributarios están atados a la

Traducción libre. 
actividad económica (Castañeda, 2012), y además en épocas difíciles la demanda de bienes públicos se incrementa. Esto significa una disminución de los ingresos públicos junto a una presión por el aumento del gasto, lo que lleva al endeudamiento como instrumento de financiación a corto plazo.

\section{LOS GANADORES DEL CONSENSO DE WASHINGTON}

Ahora se hará una breve revisión en que se relacionan las políticas propias del Consenso con los intereses del capital financiero. Así, se muestra cómo algunos puntos considerados en la Tabla 1 son funcionales para el inversionista, más allá de las pretensiones de los defensores del modelo de presentarlo como benéfico para la sociedad en su conjunto.

Cabe indicar que cuando se piensa en un inversionista se deben considerar dos momentos: en el primero se toma la decisión de invertir en determinado mercado, lo que supone tener en cuenta el marco legal del país en que se desea invertir, el estado de la economía y el orden público; el segundo momento se relaciona con la posibilidad de hacer efectivo su beneficio, donde influyen aspectos como la tasa de cambio y los mecanismos que existen para hacer las transferencias al exterior ${ }^{3}$. A continuación se indica cómo diferentes políticas tratadas por el Consenso abordan estos momentos y brindan seguridad al inversionista.

\section{La independencia del banco central}

Con medidas como la independencia del banco central se busca que las preocupaciones inmediatas del Gobierno no influyan en las decisiones del emisor, al restringirse aparentemente la posibilidad de financiar el déficit fiscal con emisión monetaria. Si bien con esto se evita que el Gobierno opte por el impuesto inflacionario, ello no excluye la posibilidad de que la emisión monetaria se privatice a partir de la posibilidad de la colocación de recursos de crédito por la banca privada y su financiamiento del gasto público.

Lo anterior además supone que las tasas de interés en la economía se establecen por el libre juego de la oferta y la demanda de los recursos financieros. Así, se limita la intervención estatal en la materia y se pretende evitar que un gobierno, en aras de atraer la inversión a corto plazo, termine generando inflación y depreciando su moneda local, a tal punto que haga inviable la conversión de los capitales en el país a moneda extranjera (e.g., dólares o euros).

Sin embargo, la posible injerencia del Estado en las tasas de interés a través de las instituciones financieras en que tiene

3 Acá se asume un inversionista que tiene la libertad y la posibilidad real de elegir entre portafolios factibles en diferentes países, por lo que está latente la inversión en el mercado de capitales (por ejemplo en bonos de deuda pública). En síntesis, se asume un inversionista muy particular y se excluye la inversión de los excedentes por parte de las familias. 
participación, asimismo sugiere limitar ese poder a través de la privatización. A modo de ejemplo, con el acuerdo Stand-By $y^{4}$ firmado por Colombia con el Fondo Monetario Internacional (FMI) correspondiente al primer Gobierno de Álvaro Uribe (2002-2006), se acordó la privatización de la banca pública $\mathrm{y}$, en particular, como meta para el 31 de diciembre de 2003, se fijó la privatización de Bancafé (Castañeda, 2013).

Por lo tanto, la imposibilidad del financiamiento a partir de la emisión monetaria y la recurrente privatización del sector bancario abren una nueva posibilidad para el incremento del endeudamiento público, a través de la colocación de títulos valores como bonos tanto en el mercado interno como en el externo. Si se revisa la dinámica de la deuda en algunos países de la región (Figura 1), se evidencia su dependencia del contexto en lugar de su racionamiento 5 . Por ejemplo, en Argentina la deuda creció exponencialmente durante la crisis económica de inicios de este siglo; asimismo, en Colombia se observa un aumento sostenido durante la segunda mitad de los noventa con ocasión del proceso de endeudamiento subnacional que se generó por la caída de las transferencias y las mayores atribuciones de gasto (Bonet, Pérez \& Ayala, 2014).

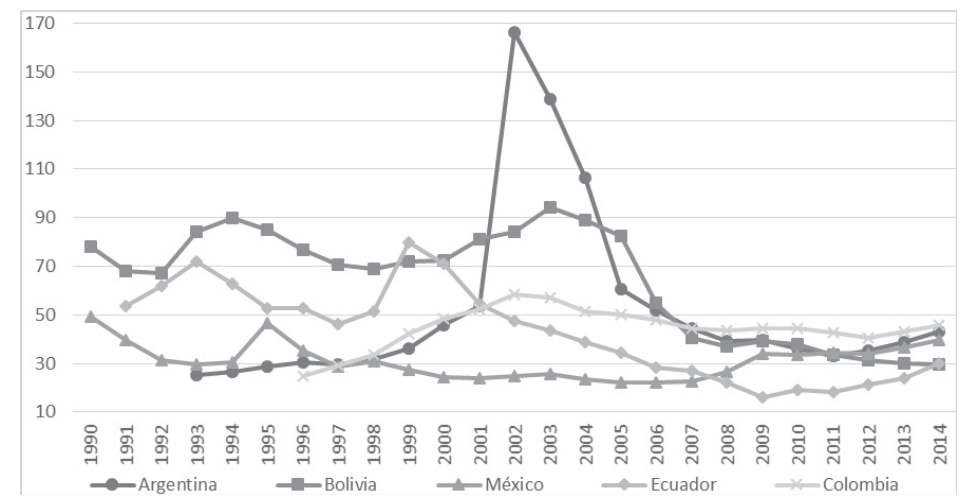

Figura 1. Deuda pública como porcentaje del PIB en algunos países de América Latina (1990-2014).

Fuente: elaboración propia con base en datos de la CEPAL. El nivel de agregación es el sector público no financiero.

\footnotetext{
$\overline{4} \quad$ Este es un tipo de acuerdo que se firma entre un Gobierno y la banca multilateral sobre préstamos condicionados a ajustes de política económica.

5 Como debería ocurrir si las políticas del Consenso realmente atacaran las causas de la deuda pública, tras el supuesto de que esta es la causante de las crisis económicas.
} 


\section{Tasa de cambio}

Además de la posibilidad de obtener una rentabilidad atractiva, el inversionista extranjero requiere poder hacer efectiva dicha ganancia. En tal sentido, se hace indispensable tener una tasa de cambio que no vulnere la rentabilidad en moneda extranjera, lo que significa controlar la devaluación y asegurar que existan las divisas suficientes para hacer el respectivo cambio. En consecuencia, desde los noventa se ha promovido una política aperturista con la esperanza de alcanzar un flujo exportador que garantice una entrada constante de divisas, aunque desafortunadamente ello no se acompañó de estrategias para mejorar la capacidad competitiva de la industria nacional ni se diversificaron las exportaciones.

Además, otra contradicción en las recomendaciones del Consenso de Washington se evidencia cuando la liberalización del mercado de capitales limita el margen de acción de los gobiernos para evitar la estampida de capitales en épocas de crisis o inestabilidad, de manera que no es factible por vía de la regulación impedir las profundas depreciaciones de la moneda, cuyos potenciales perdedores son los nacionales endeudados en moneda extranjera y también los inversionistas que requieren reconvertir sus capitales a dólares, por ejemplo. Es decir, que los instrumentos que permitirían afrontar las posibles crisis cambiarias se reducen al uso de las reservas internacionales y a la firma de acuerdos de rescate y prevención con órganos multilaterales, caso del FMI y el Banco Mundial.
Al respecto, en el artículo IV, sección 3 del convenio constitutivo del FMI, se manifiesta que este supervisará con empeño las políticas de tipo de cambio seguidas por los países miembros. Con interés expositivo, y para el caso colombiano, el 3 de diciembre de 1999 , a partir de la carta de intención del Ministerio de Hacienda y Memorando Técnico de Entendimiento (MTE), se solicitó la suscripción de un acuerdo para la efectiva aplicación de políticas económicas, entre las que se encontraba la eventual disposición de divisas para enfrentar los requerimientos de los inversionistas hasta el año 2002 por cerca de 2700 millones de dólares, esto bajo un contexto de pérdida de reservas internacionales por la salida de capitales y la disminución de las exportaciones por la baja en el precio de los commodities (Castañeda, 2013).

Según lo anterior, $\mathrm{y}$ frente a las limitaciones de las autoridades económicas para controlar los movimientos de capitales durante las crisis externas, los acuerdos tipo Stand-By con el FMI operan como salvavidas, los cuales se suelen acompañar de condicionamientos que buscan ahondar las políticas de liberalización del mercado. Según la Contraloría General de la República de Colombia (2003), "el FMI ha creado un conjunto pragmático de políticas y procedimientos conocido con el término de condicionalidad, que rigen el uso de sus recursos por parte de los países que a ellos acceden". Dichas políticas y procedimientos, que hacen parte de los planes de acción de 
programas de ajuste auspiciados por los organismos multilaterales, deben ser implementados por aquellos países que acceden a los recursos de crédito.

\section{Privatización y descentralización}

La privatización y la descentralización son procesos que van de la mano, en la medida que permiten que el Gobierno central se preocupe de aquellas funciones en las que supuestamente se requiere que opere de manera directa, caso de las políticas de seguridad nacional, la administración de justicia y el fomento económico, y traslade a los gobiernos subnacionales las responsabilidades de proveer ciertos bienes públicos con la contraprestación de girar los recursos necesarios o asignar base tributaria. Esta descentralización, adicionalmente, se promueve enfatizando en que así se favorece una mayor participación del ciudadano en la fiscalización del uso que se hace del erario, y que además se facilita la identificación de las necesidades de los ciudadanos por parte de los gobiernos municipales y departamentales.

De manera complementaria, con la descentralización y de acuerdo con la facilidad de generar exclusión en la prestación de ciertos servicios como la educación y la salud, se fundamenta la idea de la privatización como mecanismo para introducir eficiencia en la prestación de estos servicios, pues se presume que el empresario privado debe ser competitivo en un entorno en que los ciudadanos son libres de elegir según sus preferencias. De esta manera, la función del municipio (o gobierno local) termina simplificada en buena parte a la identificación de aquellos individuos que requieren ser subsidiados ${ }^{6}$.

El cambio de los subsidios a la oferta por subsidios a la demanda crea una oportunidad de negocio para que los privados entren a suplir el rol del Estado en la provisión de bienes y servicios, pero claro está que el sector público sigue fungiendo como financiador de esas iniciativas, en la medida que se constituye en cliente de última instancia. Sin embargo, el Estado necesita recursos para adquirir los bienes y los servicios que antes producía, de suerte que las demandas de recaudación se mantienen, y se genera una discusión en relación con quién debería encargarse de recaudar, si el nivel central o el descentralizado.

Para que la descentralización funcione, se hace necesario que exista alguna independencia entre los gobiernos nacionales y los subnacionales, de modo que las decisiones de las autoridades locales se correspondan con las necesidades y demandas de sus poblaciones. Por ello, la elección popular de alcaldes fue una constante entre la segunda mitad de los ochenta y la primera mitad de los noventa

\footnotetext{
$\overline{6} \quad$ La privatización se fundamenta en la idea de introducir eficiencia en la prestación de servicios como la educación y la salud, suministrando a su vez asistencia temporalmente a los excluidos del mercado a partir de políticas de subsidio a la demanda.
} 
en América Latina, aunque tras la descentralización política se han planteado problemas relacionados con el modo como se financian las iniciativas locales, que se puede hacer cediendo base tributaria o incrementando las transferencias.

Uno de los países que ha tomado el primer camino en la región es Brasil, donde un tercio de la recaudación total se realiza en los estados a partir del impuesto a la circulación de mercaderías y servicios (ICMS), que funciona como el IVA. Colombia, por su parte, ha optado por las transferencias, lo cual ha limitado las decisiones de gasto en los departamentos y municipios al estar atadas a la realización de gasto en determinadas cuantías y rubros como educación y ampliación de acueducto y alcantarillado. Cabe notar que esto fue causa del caos que se vivió con el sobreendeudamiento subnacional a finales de los noventa en el país, dado el creciente financiamiento del gasto territorial a través de deuda pública, lo que evidenció la necesidad de un marco normativo de responsabilidad y transparencia fiscal, cuyos pilares se encuentran consignados en las leyes 358 de 1997, 549 y 550 de 1999, 617 de 2000 y 819 de 2003 .
Así las cosas, en lugar de que el gasto público se haya reducido de manera coherente con el reclamo por una menor intervención estatal y el uso más eficiente de los recursos públicos, lo que se ha experimentado desde la apertura económica es su crecimiento (Figura 2), hecho común en Latinoamérica. En efecto, esto ha ocurrido porque implícitamente el Consenso de Washington requiere que el Estado garantice el pago de la deuda, externa e interna, y financie las iniciativas privadas cuando se trate de invertir en sectores que anteriormente eran reservados a la intervención pública.

Asimismo, si se analiza el comportamiento del gasto por servicio de la deuda (Figura 3), no se constata siempre un comportamiento decreciente, que sería lo esperado si las políticas del Consenso hubieran sido efectivas para controlar esta variable, dada su lectura sobre la injerencia de ella en las crisis. De hecho, lo que se verifica es que este rubro del gasto tiende a ser contracíclico, crece en periodos de desaceleración económica, en especial si se considera su dinámica hacia la segunda mitad de los noventa. 


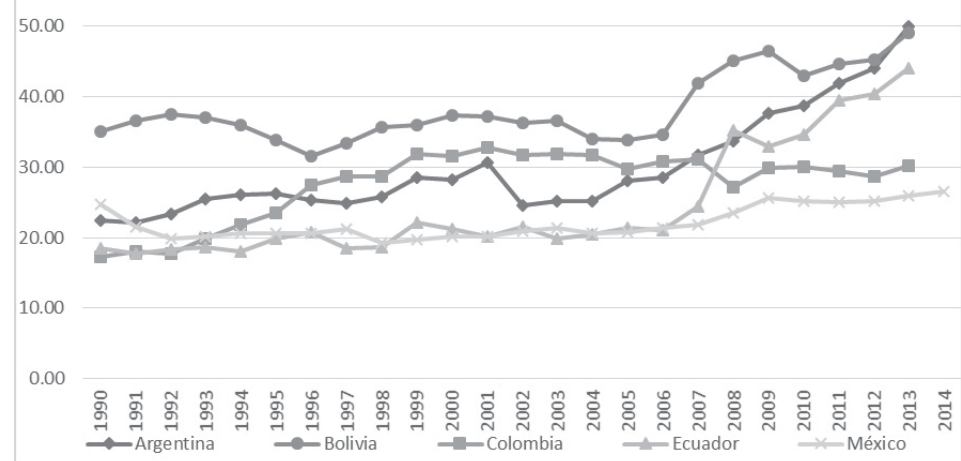

Figura 2. Gasto público total como porcentaje del PIB en algunos países de América Latina (1990-2014)

Fuente: elaboración propia con base en datos de la CEPAL. El nivel de agregación es el sector público no financiero.

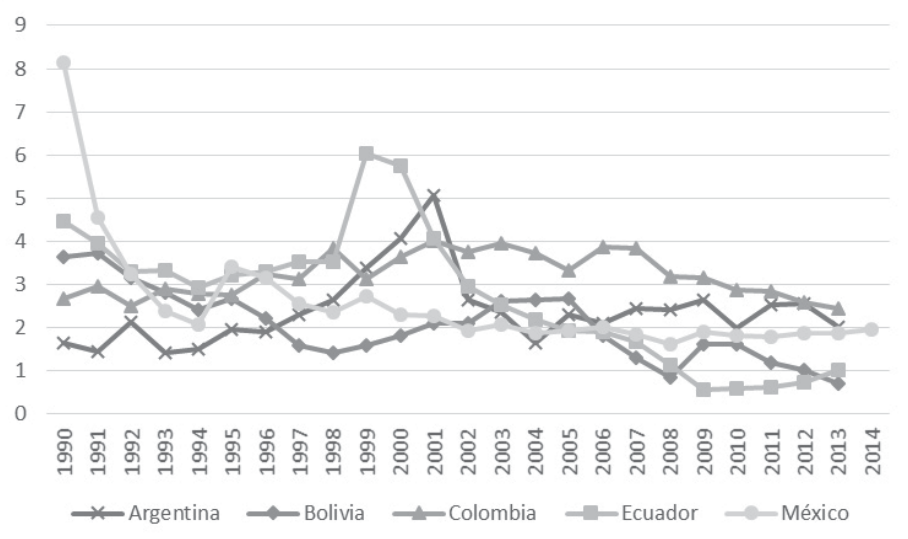

Figura 3. Servicio de la deuda como porcentaje del PIB en algunos países de América Latina (1990-2014).

Fuente: elaboración propia con base en datos de la CEPAL. El nivel de agregación es el sector público no financiero. 
RESULTADOS DE LA IMPLEMENTACIÓN DEL CONSENSO DE WASHINGTON

El Consenso de Washington encontró eco en las prácticas de los diferentes gobiernos de América Latina entre los ochenta y los noventa, pues como ya se trató, en buena parte constituía un condicionamiento de organismos como el FMI para firmar acuerdos con los respectivos países y brindar confianza en el mercado de capitales durante episodios de desaceleración económica (Castañeda, 2013).

No obstante, estas políticas permitieron combatir problemas estructurales, como la inflación asociada a la sustitución del financiamiento de fuente externa tras la crisis de la deuda, lo que les brindó legitimidad. Por otra parte, ello no garantizó altas tasas de crecimiento, ni siquiera cercanas a las exhibidas por la región en los setenta (Figura 4).

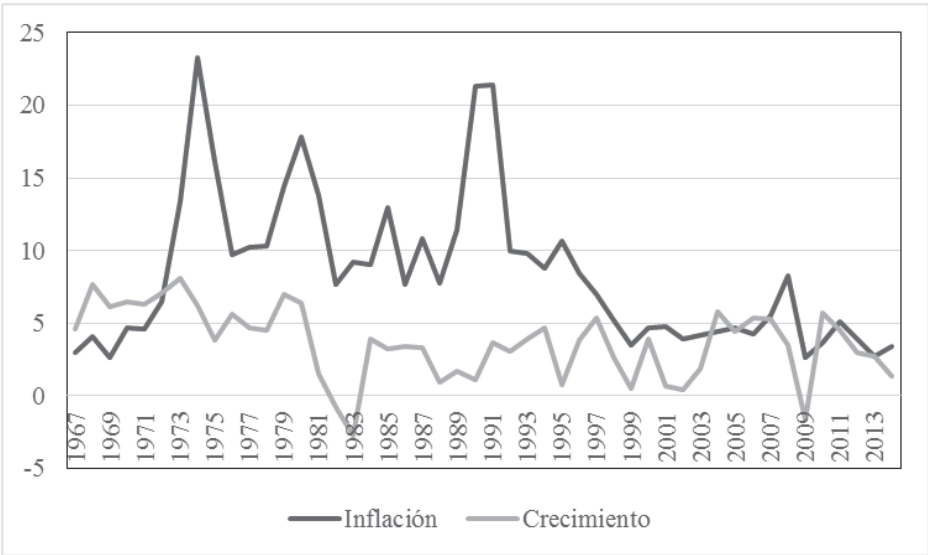

Figura 4. Comportamiento de la inflación y del crecimiento económico en América Latina (promedio) entre 1967 y 2014.

Fuente: elaboración propia con base en datos del Banco Mundial (3 de marzo de 2016).

Adicionalmente, aspectos relacionados con la redistribución fueron dejados en un segundo plano, en el supuesto de que la recuperación económica en un entorno de disciplina fiscal bastaría para que posteriormente se generaran mejores oportunidades para todos los agentes, entre ellos los trabajadores. En efecto, la discusión sobre crecimiento y equidad es álgida y cobija dos posiciones extremas, si primero se crece y luego se distribuye (enfoque neoclásico) o si se debe distribuir para crecer (enfoque keynesiano). 
Los postulados del Consenso de Washington se alinean con la primera posición, pues se enfatiza en que primero se debe crecer para luego distribuir, lo que sugiere premiar la estabilidad macroeconómica y la orientación de Estado como garante de unas condiciones de mercado idóneas para la acción privada. Esto da sentido al conjunto de políticas cubiertas por la primera versión del Consenso (véase Tabla 1), que en ningún caso previeron o se preocuparon por los retrocesos en términos de la distribución del ingreso.

Es decir, se esperaba mejorar el ingreso de los pobres a la par con el ritmo en que se beneficiaba la sociedad en su conjunto, tras la aplicación de las políticas del Consenso. Así, se previó que no bastaba con la estabilidad económica caracterizada por una inflación controlada, sino que ello se debía acompañar de medidas como la apertura comercial, para aprovechar las ventajas competitivas de cada país.

Empero, no hay claridad sobre el mecanismo a través del cual el buscado dinamismo económico favorecería un mayor ingreso para los pobres. De hecho, los resultados al respecto generan dudas sobre este enfoque. Al final de los noventa, por ejemplo, con hechos como el cierre de diversas empresas públicas, la pérdida de puestos de trabajo y la precarización de las condiciones laborales, lo que se evidenció fue una disminución en el nivel de ingresos de los trabajadores; en otros términos, se dio una redistribución factorial a favor del capital.

La Figura 5 presenta el porcentaje de la población pobre o en estado de indigencia en cinco países de América Latina entre 1985 y 2013, siguiendo para esto el enfoque del Banco Mundial que supone tomar una línea de pobreza igual a 3.1 dólares diarios (2011, en términos de Paridad de Poder Adquisitivo, PPP). No se tomaron las líneas de pobreza nacionales, porque ello implicaba una mayor pérdida de observaciones. En general, se advierte que a pesar de algunos casos aislados, la década del noventa se caracterizó por un incremento de este indicador, que solo desde el primer lustro de este siglo empezó a ceder.

Ahora, si se revisa la dinámica de la distribución del ingreso en los países de América Latina, en general se observa que entre los ochenta y los noventa hubo una profundización de la desigualdad, situación que empezó a cambiar desde los primeros años de este siglo (LópezCalva \& Lustig, 2010). De acuerdo con López-Calva y Lustig (2010), dicha mejora dependió de factores como un mayor gasto público focalizado en los pobres a través de transferencias, y un cambio político en que los partidos de centroizquierda quedaron al mando del Ejecutivo en varios países de la región. 


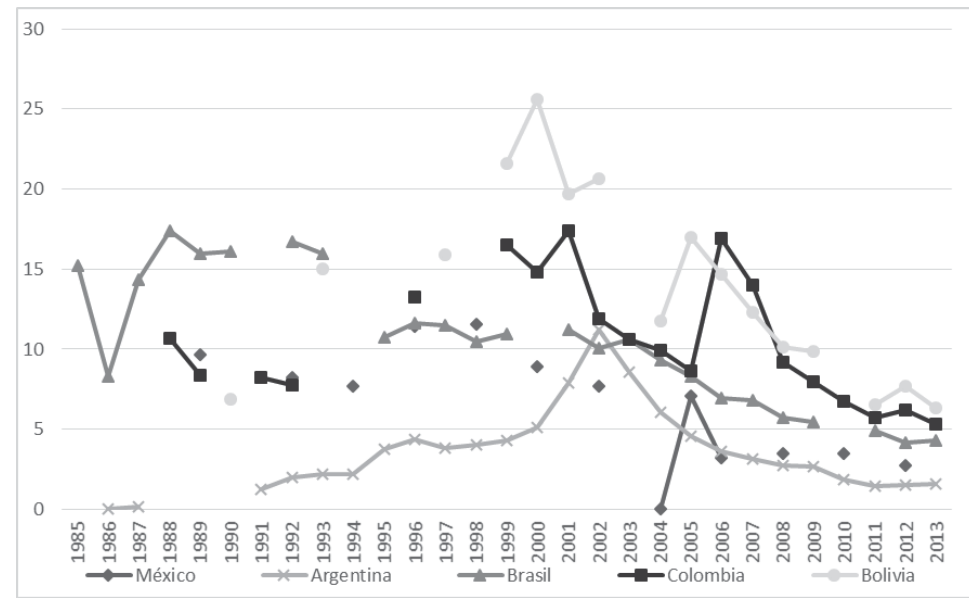

Figura 5. Población de cinco países de América Latina con un ingreso diario inferior a 3.1 dólares (2011 PPP).

Fuente: elaboración propia con base en datos del Banco Mundial.

Por otra parte, la Figura 6 muestra que en general hubo un crecimiento de la desigualdad, medida a través del Gini, en la región a lo largo de los noventa, década en que estuvo especialmente vigente el Consenso de Washington. Sin embargo, lo importante acá es que también se verifica que la profundidad de los cambios en la materia fueron disímiles, sobresaliendo casos como el de Colombia, que exhibió un dramático aumento de la desigualdad en la primera mitad de los noventa, o Venezuela que, por otro lado, es el país que mayor éxito presenta en la lucha contra este fenómeno (particularmente desde 2005) ${ }^{7}$.
Si bien el Consenso de Washington en un comienzo pretendió solucionar la pobreza al reemplazar programas universales por la focalización del gasto, las condiciones de acceso a los servicios sociales no fueron suficientes para lograr ese cometido (Uribe, 1992). De acuerdo con Sen (2000), se requiere ampliar considerablemente el derecho de acceso a factores y recursos en igualdad de oportunidades para que los beneficiarios desarrollen sus capacidades y habilidades, de modo que puedan incorporarse efectivamente a los mercados.

\footnotetext{
Lo que está en consonancia con las aseveraciones de López-Calva y Lustig (2010).
} 


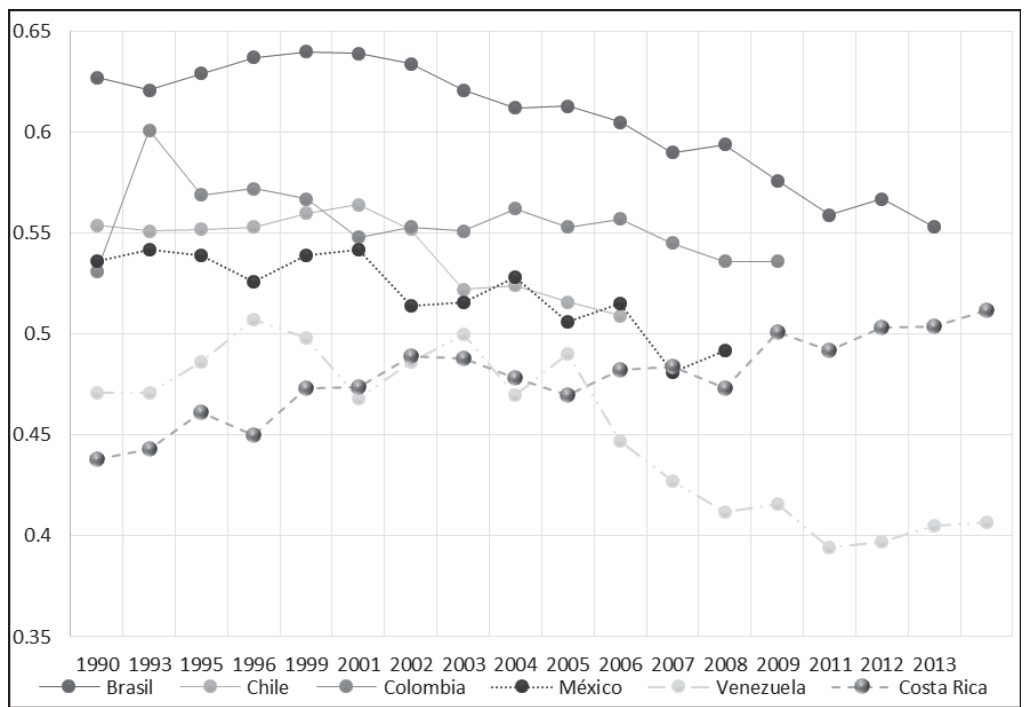

Figura 6. Coeficiente de Gini en algunos países de América Latina entre 1989 y 2013. Fuente: elaboración propia con base en datos de la CEPAL. Se tomaron solo seis países para facilitar la observación y porque son los que tienen un mayor número de observaciones para el índice de Gini en el periodo de estudio.

Según la Figura 7, se abre un gran interrogante sobre la efectividad en materia de equidad de las políticas del Consenso de Washington. En efecto, considerando que la pobreza y la distribución se constituyen en dos problemas serios y prioritarios en Latinoamérica, es necesario propiciar un cambio de agenda, de tal manera que en el centro de las reformas se encuentre la distribución del ingreso, de la riqueza y de la tierra.

Como se observa en la Figura 7, no solo los países de América Latina, por lo general, parten de una distribución del ingreso más desigual en relación con sus pares desarrollados, sino que además el efecto redistributivo de sus políticas fiscales (i.e., tributos y gasto público) es reducido. En efecto, autores como Steiner y Cañas (2013) y Jiménez (2015) ponen de manifiesto la insuficiencia de la política económica en América Latina para tratar fenómenos como la desigualdad. Una importante razón para esto es la renuncia de base tributaria que suponen diversos beneficios tributarios; por ejemplo, las exenciones que muchas veces se concentran en los más ricos.

Aunque no se puede negar que el gasto público social en la región ha crecido según lo demuestran las estadísticas de organismos como la CEPAL, en diversas ocasiones este ha servido como 
instrumento político, siendo asignado sin criterios técnicos, o también ha sido presa de la corrupción (véase Gamarra, 2006, en relación con el caso colombiano).
Todo lo anterior mina la efectividad del gasto público para mejorar la distribución del ingreso y contribuye a la ilegitimidad de la función estatal.

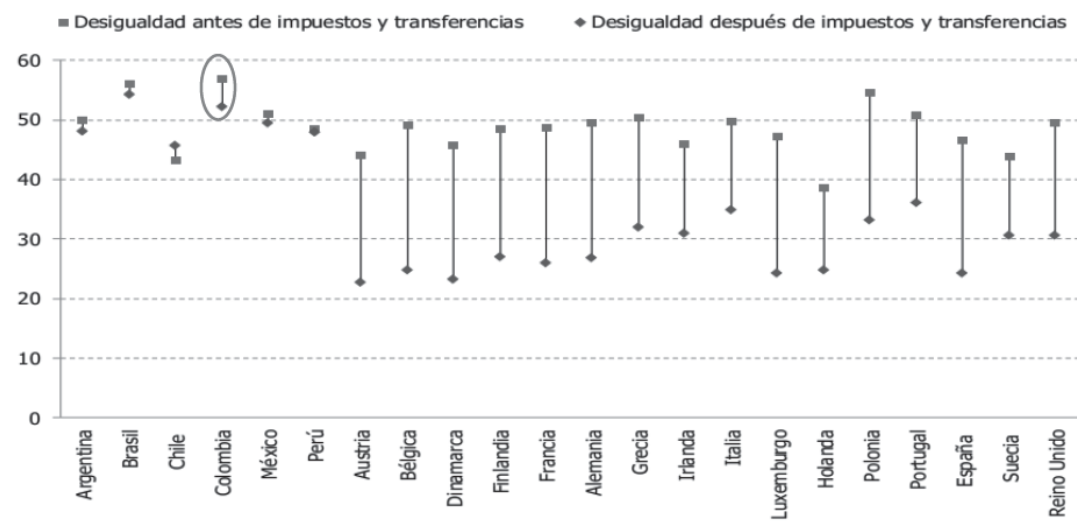

Figura 7. Desigualdad del ingreso antes y después de impuestos y transferencias.

Fuente: Steiner \& Cañas (2013, p. 2).

UNA PROPUESTA DE REFORMA TRIBUTARIA AL MODELO INSTAURADO CON EL CONSENSO DE WASHINGTON

En las secciones previas se mostró que el Consenso de Washington no implicó un mayor dinamismo en el crecimiento económico de América Latina y en su lugar sí desatendió aspectos como su latente desigualdad en la distribución del ingreso, pues de hecho, hoy es la región más desigual del mundo. Claro está que la misma concepción económica que subyace al Consenso de Washington presupone que primero se debe crecer para luego redistribuir. El problema es que ni existe asidero empírico de tal causalidad ni el desempeño económico ha sido el esperado8.

Por lo tanto, en esta última sección se presenta desde al área tributaria una alternativa de reforma que podría ser considerada buscando dos cosas, mejorar la recaudación y al mismo tiempo el potencial redistributivo del sistema impositivo. Cabe resaltar que la estrategia tras la política de reforma tributaria contenida en la primera versión del Consenso y que aún es un referente en la materia, sugiere ampliar las bases

$\overline{8}$ Por ejemplo, en la región no se han recuperado las tasas de crecimiento del PIB que se tenían en la primera mitad de los setenta. 
tributarias y reducir la incidencia de las tasas marginales, lo que implica premiar la eficiencia a costo de la progresividad.

Dicho modelo tributario, según Castañeda (2012, p. 80), ha favorecido en América Latina "la reducción de los impuestos que gravaban al comercio y a las transacciones internacionales, el moderado incremento en los impuestos sobre la renta y la importancia cobrada por [...] el IVA".
De hecho, una comparación entre las figuras 8 y 9 evidencia que efectivamente América Latina ha logrado cerrar desde los noventa parte de la brecha de recaudación que tenía con los países desarrollados y que ello se ha logrado en buena parte a través de impuestos al consumo como el IVA, pero todavía su presión tributaria es baja, y ello se explica por deficiencias en la recaudación del ISR.

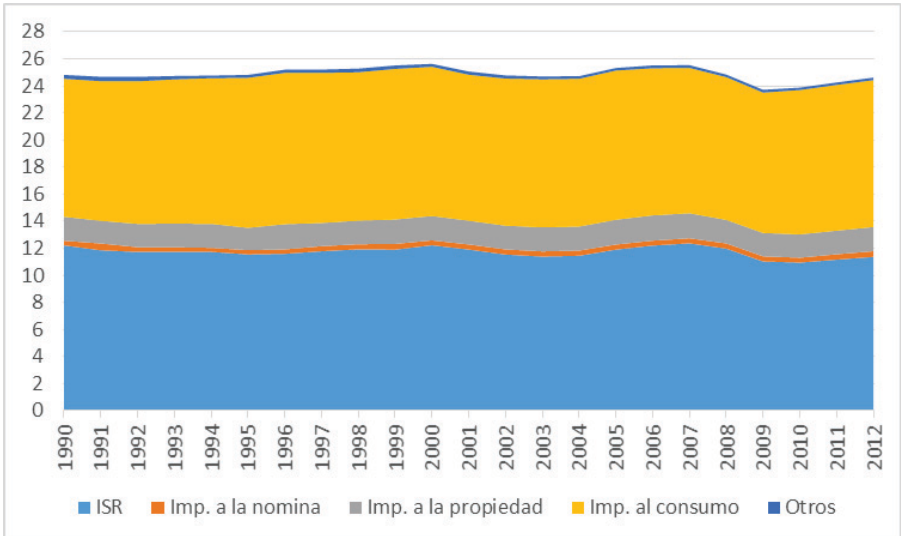

Figura 8. Recaudación (\% PIB) promedio en la OCDE por tipo de impuesto (1990-2012).

Fuente: elaboración propia con base en datos de la OCDE 


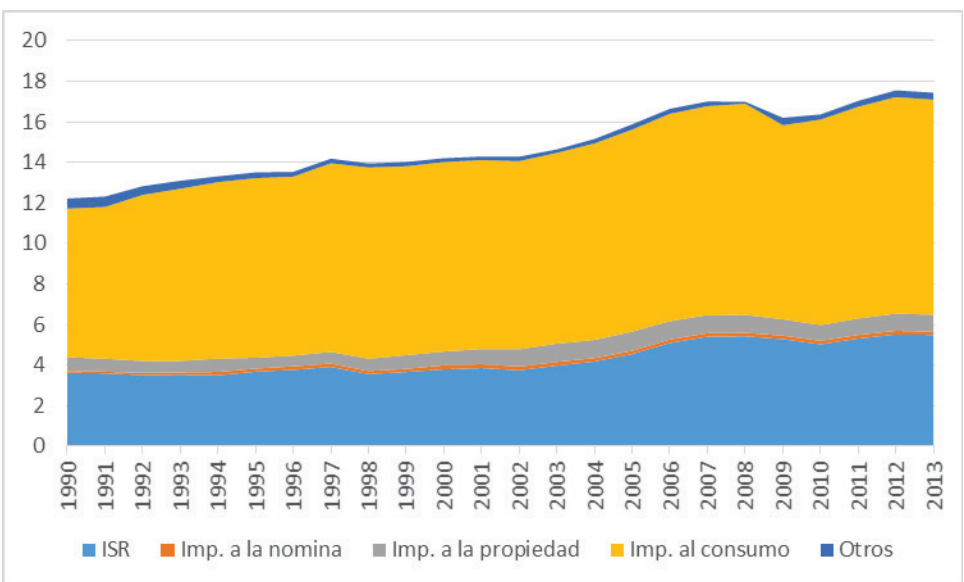

Figura 9. Recaudación (\% PIB) promedio en América Latina por tipo de impuesto (1990-2013).

Fuente: elaboración propia con base en datos de la OCDE.

Si se analiza más detalladamente la diferencia en recaudación que aún persiste entre países de la Organización para la Cooperación y el Desarrollo Económicos (OCDE) y América Latina, queda claro que en buena parte ella se explica porque las personas naturales pagan comparativamente pocos impuestos en América Latina (Figura 10). Ahora bien, esto no quiere decir que todas las personas naturales paguen poco, sino que son muchas las que quedan excluidas de la obligación, por fenómenos como la informalidad, la evasión y diversos beneficios tributarios.

Usualmente, se llama la atención sobre el riesgo que implican los impuestos directos altos para la inversión, lo que desde el mismo Consenso de Washington motivó la reducción de las alícuotas marginales máximas y puso el mayor esfuerzo de las reformas tributarias en el IVA. No obstante, es de indicar que bajo los modelos de renta mundial y las iniciativas que buscan incrementar el intercambio de información entre administraciones tributarias, caso de las propuestas de Estados Unidos (FATCA) y la OCDE, se limitan las oportunidades de los contribuyentes para reducir su carga fiscal a través de la disposición de su riqueza alrededor de mundo. Por lo tanto, hay campo para mejorar la recaudación y progresividad de los sistemas tributarios en la región, sin que ello signifique necesariamente un desestímulo a la inversión o a la actividad económica. 


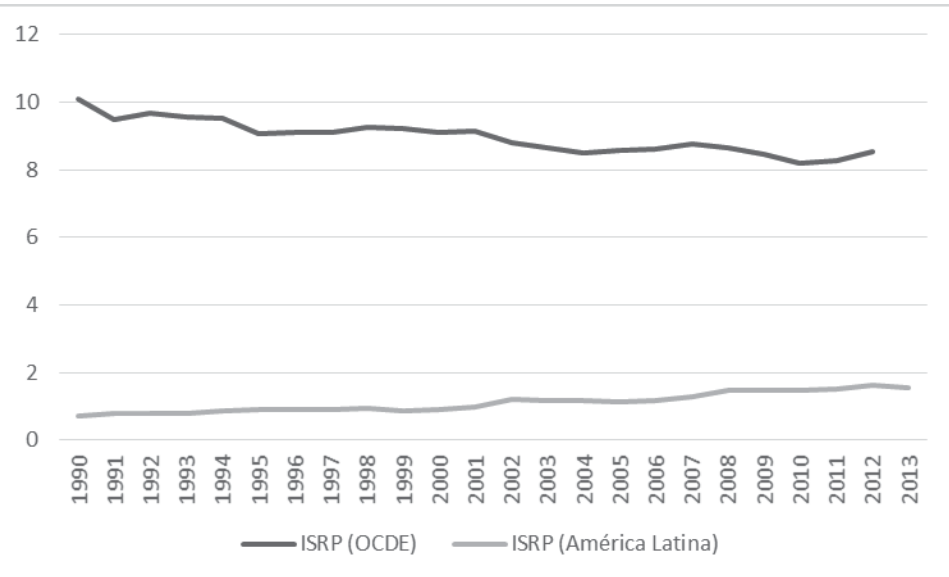

Figura 10. Recaudación del impuesto sobre la renta personal (\% PIB) en la OCDE y América Latina (1990-2013).

Fuente: elaboración propia con base en datos de la OCDE.

Es decir, que se debe aumentar la carga tributaria, sin que ello signifique necesariamente un mayor esfuerzo para quienes ya pagan impuestos. Se trataría de limitar la incidencia de diversos tratamientos tributarios especiales que limitan la base impositiva, en muchos casos concentrados en las altas rentas, y fortalecer la capacidad fiscalizadora de las administraciones tributarias dotándolas de instrumentos como mayor información exógena o la promoción del uso del sistema bancario por parte de los contribuyentes. Esto último facilitaría el cruce de información y permitiría identificar a una importante cantidad de evasores que se esconden tras la informalidad.

Incluso limitar la incidencia de los beneficios tributarios, especialmente para el caso de las rentas más altas, y prestar atención a la informalidad permiten abordar lo que para la CEPAL (2013) es la reciprocidad asimétrica y excluyente respectivamente. Estas constituyen características de los sistemas tributarios latinoamericanos que desincentivan el cumplimiento tributario de los contribuyentes. Además, si se tiene en cuenta la caída de los precios internacionales de los commodities, esto sugiere una oportunidad adicional para desligar la suerte de los ingresos públicos de la explotación de los recursos naturales.

Muchos gobiernos, para tratar con las presiones de diversos grupos de interés, han creado sendos beneficios tributarios que no solo reducen la capacidad fiscal de los Estados suponiendo una pérdida de eficiencia, sino que además afectan 
la equidad en sus dos dimensiones, la horizontal y la vertical. Así, una reforma tributaria que genere una mayor capacidad de financiamiento de gasto público de alto impacto social (e.g., transferencias condicionadas a los hogares), demanda racionalizar los beneficios tributarios, caso del tratamiento como ingresos no constitutivo que se da a las rentas de capital en muchos países ${ }^{9}$ o la separación que se hace entre rentas ordinarias y extraordinarias, lo cual fractura la base gravable.

Con el ánimo de dar cuenta de los recursos que se podrían estar dejando de recaudar por efecto de los tratamientos diferenciales en impuestos como el IVA y el ISR, la Figura 11 indica que, en promedio, el gasto tributario en América Latina asciende a alrededor de $4.5 \%$ PIB, lo que equivale a aproximadamente el $25 \%$ de su presión tributaria actual. Ahora, si se revisa el fenómeno para el ISR en particular, Pecho (2014) indica que el gasto tributario asciende en promedio a $1.85 \%$ del PIB, lo que permite plantear que aun cuando no se modifiquen las tarifas para hacer al sistema tributario más progresivo, queda campo para mejorar la recaudación sin afectar excesivamente a la actividad económica.

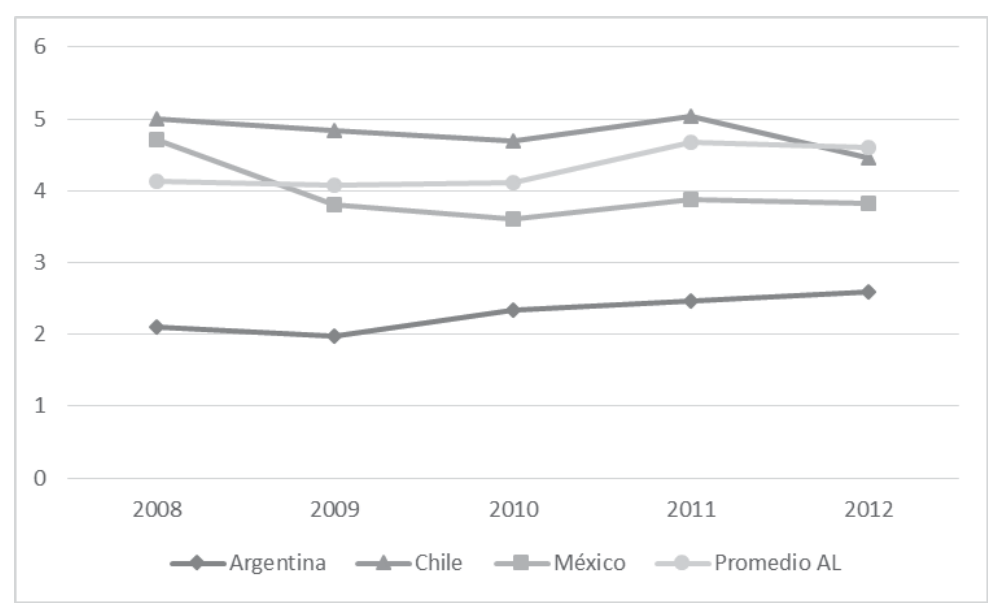

Figura 11. El gasto tributario en algunos países de América Latina entre 2008 y 2012. Fuente: elaboración propia con base en datos de Pecho (2014).

$\overline{9}$ Por ejemplo, colocaciones financieras y ganancias de capital en venta de bienes inmuebles o acciones. 
Por otro lado, depender mucho de un impuesto como el IVA, según los resultados de Corbacho, Fletes y Lora (2012), al final parece tornar más cíclico el recaudo, de modo que cuando cae la actividad económica se profundizan algunos problemas como el déficit fiscal. En otras palabras, la alta semielasticidad de los impuestos al consumo con respecto a la brecha de producción, esto sumado a la falta de un fondo de estabilización (ahorro), hace más probable que en épocas de crisis se deba recurrir a reformas que incrementan las tarifas (véase e.g., Castañeda, 2016), lo cual afecta la recuperación económica y hace más inestable el entorno jurídico y normativo.

En particular, la Figura 12 indica que si bien en los países desarrollados también los impuestos al consumo presentan una alta semielasticidad, el shock de una desaceleración económica es mayor en países como los latinoamericanos, si se tiene en cuenta la baja recaudación por otras fuentes como el impuesto sobre la renta personal (ISRP), lo cual también se manifiesta en la Figura 12 por la baja semielasticidad de esta fuente fiscal en relación con la producción.

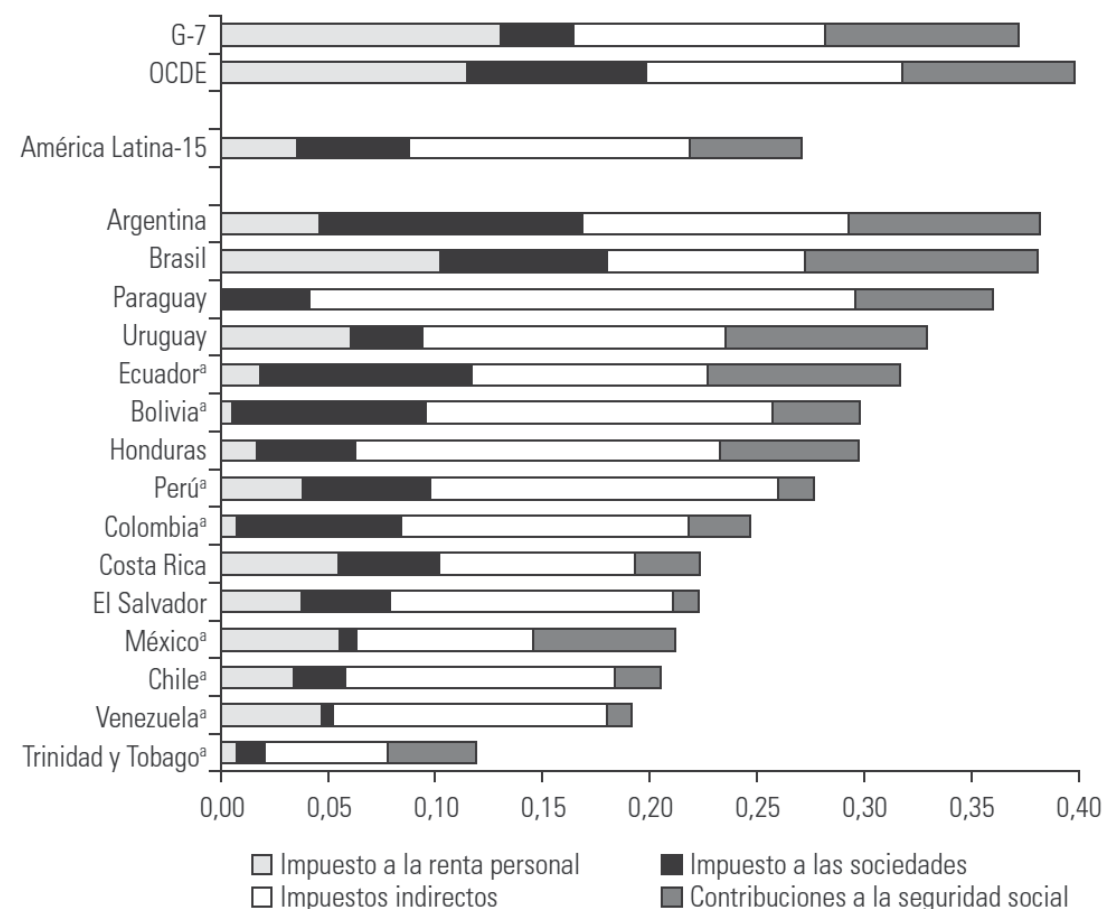

Figura 12. Semielasticidades de los impuestos en relación con la producción (\% del PIB, o del PIB excluyendo recursos naturales).

Fuente: Corbacho, Fletes \& Lora (2012, p. 83). 


\section{CONCLUSIONES}

La aplicación sin mayor análisis de ciertos principios como la minimización de la intervención estatal, bajo los que se construyó el Consenso de Washington, ha generado una mayor vulnerabilidad de las economías latinoamericanas ante las crisis financieras, que con la globalización han ganado la condición de mundiales. Por ejemplo, actualmente los gobiernos rara vez cuentan con los instrumentos para limitar una estampida de capitales más allá de la confianza que genere su disponibilidad de reservas internacionales y su capacidad de firmar acuerdos con organismos como el FMI, los cuales normalmente se condicionan a la profundización del modelo.

Asimismo, se encuentra un quiebre a la baja en el crecimiento económico en la región desde mediados de los ochenta, lo cual impuso restricciones para generar un flujo de financiamiento (i.e., impuestos) que permitiera emprender programas de gasto social lo suficientemente continuos y profundos como para atender problemas álgidos en América Latina, como la pobreza y la desigualdad. De hecho, es notable que el periodo en que más dinámica fue la adopción de las políticas del Consenso de Washington en la región haya coincidido con al aumento de los índices de pobreza y desigualdad, lo cual muestra que un modelo garante de las necesidades de los inversionistas no asegura una mejora generalizada en las condiciones económicas y sociales de un país.
Además, se evidencia que fenómenos como el endeudamiento y el aumento de los déficits fiscales y comerciales tienden a aparecer precisamente durante periodos de desaceleración económica, lo cual genera dudas sobre presunciones que se hacían bajo el Consenso de Washington, en que era la indisciplina fiscal una de las principales causas de las crisis. Sin embargo, el conjunto de políticas que aparecen en la Tabla 1 acentúan la dependencia de las economías locales a los vaivenes internacionales, lo que incorporá mayores riesgos a la gestión de los gobiernos y reduce su capacidad de respuesta.

Por otro lado, en aras de promover la inversión se han aceptado paradigmas nocivos en áreas como la tributación, en que aún se sigue pensando que un tipo de reforma adecuada al sistema impositivo supone aumentar el IVA y reducir las tarifas marginales en el caso de los ISR, so pretexto de que la baja de recaudación se recuperará a través de aumentos de las bases tributarias (incorporación de nuevos contribuyentes). No obstante, esto no es consecuente con las observaciones que se pueden hacer con respecto al nivel de recaudación por impuestos entre países desarrollados y en vías de desarrollo, en que se manifiesta una baja recaudación directa, especialmente asociada al ISRP, en América Latina.

Lo anterior, sumado a iniciativas que bajo el principio de renta mundial buscan controlar la evasión a través del fortalecimiento de los canales 
de intercambio de información entre administraciones tributarias (e.g., la iniciativa FATCA y el modelo de la OCDE), invita a incrementar la carga tributaria y al mismo tiempo a favorecer la progresividad del sistema. Por ejemplo, y sin perjuicio notable para la inversión, se puede eliminar la distinción que usualmente se hace entre rentas de trabajo y rentas de capital, junto a otros beneficios tributarios que además de significar una renuncia a recaudar, transgreden principios como la equidad y debilitan el pacto fiscal (CEPAL, 2013). Empero, esto deberá estar acompañado de una mayor atención a la informalidad y la evasión, para que se logre un aumento importante de la presión tributaria en que participen quienes actualmente están excluidos del pacto fiscal.

\section{REFERENCIAS}

Bonet, J., Pérez, G. \& Ayala, J. (2014). Contexto histórico y evolución del SGP en Colombia. Working paper de Economía Regional 205. Cartagena: Banco de la República.

Castañeda, V.M. (2012). Una revisión de los determinantes de la estructura y el recaudo tributario: el caso latinoamericano tras la crisis de la deuda externa. Cuadernos de Economía, 31(58), 77-112.

Castañeda, V.M. (2013). La tributación en América Latina desde la crisis de la deuda y el papel del legislativo en Colombia. Revista de Economía Institucional, $15(28), 257-280$.

Castañeda, V.M. (2016). Las crisis económicas y el escenario político en la introducción de reformas tributarias. La experiencia argentina (1980-2010) y una constatación para Latinoamérica. Cuadernos de Economía, 35(67), 173-206. doi: 10.15446/ cuad.econ.v35n67.52466.

CEPAL (2013). Panorama fiscal de América Latina y el Caribe. Reformas tributarias y renovación del pacto fiscal. Santiago de Chile: CEPAL. Recuperado de http:// www.cepal.org/publicaciones/xml/6/49276/PanoramaFiscaldeALC.pdf

Contraloría General de la República (2003). Evaluación de los acuerdos de Colombia - FMI 1999, 2003. Bogotá: CGR.

Corbacho, A., Fretes, V. \& Lora, E. (Eds.) (2012). Recaudar no basta. Los impuestos como instrumento de desarrollo. Washington: BID. 
Gamarra, J. (2006). Pobreza, corrupción y participación política: una revisión para el caso colombiano. Working paper de Economía Regional 70. Cartagena: Banco de la República.

Giraldo, C. (2009). Finanzas públicas en América Latina: la economía política. Bogotá: Ediciones Desde Abajo.

Hayek, F. (2004). Camino de servidumbre. Madrid: Alianza.

Jiménez, J.P. (Ed.) (2015). Desigualdad, concentración del ingreso y tributación sobre las altas rentas en América Latina. Santiago de chile: CEPAL. Recuperado de http://www.cepal.org/es/publicaciones/37881-desigualdad-concentracion-delingreso-y-tributacion-sobre-las-altas-rentas-en

López-Calva, L. \& Lustig, N. (2010). Explaining the Decline in Inequality in Latin America: Technological Change, Educational Upgrading and Democracy. In L. López-Calva \& N. Lustig (eds.) Declining Inequality in Latin America: a Decade of Progress? USA: Brookings Institution Press/Programa de las Naciones Unidas para el Desarrollo (PNUD).

Pecho, M. (2014). Gastos tributarios en América Latina: 2008-2012. Working paper 2-2014. Ciudad de Panamá: CIAT.

Rodrik, D. (1996). Understanding Economic Policy Reform. Journal of Economic Literature, 34, 9-41.

Sen, A. (2000). Desarrollo y libertad. México D.F.: Planeta Mexicana.

Steiner, R. \& Cañas, A. (2013). Tributación y equidad en Colombia. Bogotá: DNP.

Uribe, F. (1992). Desarrollo regional en el nuevo entorno de políticas públicas: un nuevo rol para el Estado latinoamericano. Cuadernos de Economía, 12(17), 7-44.

Williamson, J. (1990). What Washington Means by Policy Reform. In Latin American Adjustment: How Much Has Happened? Washington: Institute of International Economics.

Williamson, J. (2004). A Short History of the Washington Consensus. In Lecture: From the Washington Consensus Towards a New Global Governance. Barcelona, September, 2004. 